\title{
Digital subtraction myelography for the identification of spontaneous spinal CSF-venous fistulas
}

\author{
Wouter I. Schievink, MD, ${ }^{1}$ Franklin G. Moser, MD, MMM, ${ }^{2}$ M. Marcel Maya, MD, ${ }^{2}$ and \\ Ravi S. Prasad, MD²
}

Departments of ${ }^{1}$ Neurosurgery and ${ }^{2}$ Radiology, Cedars-Sinai Medical Center, Los Angeles, California

\begin{abstract}
OBJECTIVE In most patients with spontaneous intracranial hypotension, a spinal CSF leak can be found, but occasionally, no leak can be demonstrated despite extensive spinal imaging. Failure to localize a CSF leak limits treatment options. The authors recently reported the discovery of CSF-venous fistulas in patients with spontaneous intracranial hypotension and now report on the use of digital subtraction myelography in patients with spontaneous intracranial hypotension but no CSF leak identifiable on conventional spinal imaging (i.e., non-digital subtraction myelography).
\end{abstract}

METHODS The patient population consisted of 53 consecutive patients with spontaneous intracranial hypotension who underwent digital subtraction myelography but in whom no spinal CSF leak (i.e., presence of extradural CSF) was identifiable on conventional spinal imaging.

RESULTS The mean age of the 33 women and 20 men was 53.4 years (range 29-71 years). A CSF-venous fistula was demonstrated in 10 (19\%) of the 53 patients. A CSF-venous fistula was found in $9(27 \%)$ of the 33 women and in 1 $(5 \%)$ of the 20 men $(p=0.0697)$. One patient was treated successfully with percutaneous injection of fibrin sealant. Nine patients underwent surgery for the fistula. Surgery resulted in complete resolution of symptoms in 8 patients (follow-up 7-25 months), and in 1 patient, symptoms recurred after 4 months.

CONCLUSIONS In this study, the authors found a CSF-venous fistula in approximately one-fifth of the patients with recalcitrant spontaneous intracranial hypotension but no CSF leak identifiable on conventional spinal imaging. The authors suggest that digital subtraction myelography be considered in this patient population.

http://thejns.org/doi/abs/10.3171/2015.10.SPINE15855

KEY WORDS headache; low-pressure syndrome; cerebrospinal fluid; intracranial hypotension; technique

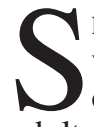
PONTANEOUS intracranial hypotension has become a well-recognized and increasingly diagnosed cause of headaches, especially in young and middle-aged adults. ${ }^{9,11}$ When brain MRI findings and clinical presentation are typical of spontaneous intracranial hypotension, then treatment with epidural blood patching can proceed without the need for further imaging. In patients with normal brain MRI findings and in those with persistent symptoms despite epidural blood patching, spinal imaging often is recommended to search for an underlying spinal CSF leak. Although in most patients a spinal CSF leak can be found, in some patients with spontaneous intracranial hypotension, no CSF leak can ever be demonstrated despite extensive evaluation with various imaging modalities such as MRI, radionuclide cisternography, CT myelography, T2-weighted MRI myelography, and intrathecal Gd- enhanced MRI myelography. ${ }^{1-3,8-12,15,17}$ This failure to localize a CSF leak can limit treatment options.

We recently reported the fortuitous discovery of CSFvenous fistulas in some patients with spontaneous intracranial hypotension..$^{13}$ These fistulas were found not only in patients with spinal CSF leaks but also in patients without any detectable CSF leak. We now report on the yield of finding a CSF-venous fistula by performing digital subtraction myelography (DSM) in patients with spontaneous intracranial hypotension but no CSF leak identifiable on conventional spinal imaging (i.e., non-DSM).

\section{Methods}

This study was approved by the Cedars-Sinai Medical Center institutional review board. 
TABLE 1. ICHD-3 diagnostic criteria for headache caused by spontaneous intracranial hypotension

\begin{tabular}{cc}
\hline Criterion & \multicolumn{2}{c}{ Description } \\
\hline A & Any headache fulfilling criterion C \\
\hline B & $\begin{array}{r}\text { Low CSF pressure (<60 mm CSF) \&/or evidence of CSF } \\
\text { leakage on imaging }\end{array}$ \\
\hline C & $\begin{array}{r}\text { Headache developed in temporal relation to low CSF pres- } \\
\text { sure or CSF leakage or led to its discovery }\end{array}$ \\
\hline D & Not better accounted for by another ICHD-3 diagnosis \\
\hline
\end{tabular}

The patient population consisted of a group of 53 consecutive patients with spontaneous intracranial hypotension who underwent DSM between April 1, 2013, and September 30, 2014, but had no spinal CSF leak identifiable (i.e., presence of extradural CSF) on conventional CT myelography, MRI, or MR myelography. The diagnosis of spontaneous intracranial hypotension was made using the criteria of the International Classification of Headache Disorders, Third Edition (ICHD-3) ${ }^{4}$ (Table 1).

In all patients, the DSM technique, as described by Hoxworth et al., 5,6,12 was used with some minor modifications. Briefly, DSM is performed with the patient in a state of general endotracheal anesthesia with deep paralysis and suspended respiration for maximal detail and temporal resolution. The patient is positioned prone in a biplane angiography suite with tilt-table capability. Foam padding or pillows are placed to reduce lumbar lordosis and overcome thoracic kyphosis. A fluoroscopically guided lumbar puncture is performed at the L2-3 level with a 20-gauge spinal needle. An opening pressure is obtained at this time (with the patient prone and in a state of general endotracheal anesthesia). Accurate needle positioning is confirmed with an injection of $0.5 \mathrm{ml}$ of Omnipaque. The patient is then repositioned, based on the area of interest, and the table is tilted to achieve contrast flow to the cervicothoracic spine. Finally, contrast ( $1 \mathrm{ml} / \mathrm{second})$ is injected manually while the patient's respiration is suspended for 40-60 seconds, and biplane subtraction images are acquired at 2 frames/ second. Venous pressure is not measured.

Each patient completed a Migraine Disability Assessment (MiDAS) questionnaire to assess the severity of the symptoms before and after treatment. ${ }^{16} \mathrm{~A}$ MiDAS score of 0-5 (Grade I) is considered equal to little or no disability, scores of 6-10 (Grade II) indicate mild disability, scores of 11-20 (Grade III) indicate moderate disability, and scores higher than 20 (Grade IV) indicate severe disability.

For statistical analysis, ANOVA and the Fisher exact test were used to compare groups and patient characteristics, respectively.

\section{Results}

Characteristics of the 53 patients are presented in Table 2. The mean age of the 33 women and 20 men was 53.4 years (range 29-71 years). Every patient had presented with orthostatic headache. The duration of symptoms ranged from 2 to 172 months (mean 47 months). Every patient had undergone brain MRI examination, which in $42(79 \%)$ of the patients showed 1 or more of the typical stigmata (brain sagging, pachymeningeal enhancement, and subdural fluid collections) of spontaneous intracranial hypotension, although brain MRI findings had normal-

TABLE 2. Characteristics of 53 patients with spontaneous intracranial hypotension and no CSF leak identifiable on conventional spinal imaging who underwent DSM

\begin{tabular}{|c|c|c|c|c|}
\hline \multirow[b]{2}{*}{ Variable } & \multirow[b]{2}{*}{ All Patients } & \multicolumn{2}{|c|}{ Fistula } & \multirow[b]{2}{*}{ p Value } \\
\hline & & Yes & No & \\
\hline No. $(\%)$ of patients & 53 & $10(18.9)$ & $43(81.1)$ & \\
\hline Age at diagnosis (yrs) & & & & 0.53 \\
\hline Mean (SD) & $53.4(10.7)$ & $51.8(9.6)$ & $54.3(11.0)$ & \\
\hline Median (IQR) & $54(61-47)$ & $53(60-48)$ & $55(62-47)$ & \\
\hline $\operatorname{Sex}(n[\%])$ & & & & 0.0697 \\
\hline Female & $33(62.3)$ & $9(90.0)$ & $24(55.8)$ & \\
\hline Male & $20(37.7)$ & $1(10.0)$ & $19(44.2)$ & \\
\hline Duration of symptoms (mos) & & & & 0.38 \\
\hline Mean (SD) & $47.0(43.7)$ & $37.6(39.5)$ & $49.2(44.8)$ & \\
\hline Median (IQR) & $37(63-15)$ & $19(57-11)$ & $41(68-18)$ & \\
\hline \multicolumn{5}{|l|}{ Low opening pressure $\left(<6 \mathrm{~cm} \mathrm{H}_{2} \mathrm{O}\right)(\mathrm{n}[\%])$} \\
\hline At time of initial lumbar puncture & $25(47.2)$ & $6(60.0)$ & $19(44.2)$ & 0.49 \\
\hline At time of DSM & $9(17.0)$ & $1(10.0)$ & $8(18.6)$ & 1.00 \\
\hline \multicolumn{5}{|l|}{ Positive MRI findings (n [\%]) } \\
\hline Baseline & $42(79.3)$ & $8(80.0)$ & $34(79.1)$ & 1.00 \\
\hline At time of DSM & $33(62.3)$ & $6(60.0)$ & $27(62.8)$ & 1.00 \\
\hline Normalization of MRI findings at time of DSM (n [\%]) & $9(17.0)$ & $2(20.0)$ & $7(16.3)$ & 1.00 \\
\hline CSF leak found on previous spinal imaging (n [\%]) & & & & 1.00 \\
\hline Positive & $10(18.9)$ & $2(20.0)$ & $8(18.6)$ & \\
\hline Negative & $43(81.1)$ & $8(80.0)$ & $35(81.4)$ & \\
\hline
\end{tabular}


ized in 9 of these patients by the time of DSM. Although no CSF leak was identified on recent conventional spinal imaging in any of the 53 patients, 10 patients had undergone spinal imaging between 2 and 9 years earlier that had shown the presence of a CSF leak. Eight patients had always had normal brain MRI findings and never had a CSF leak revealed by spinal imaging, but all the patients had an abnormally low opening pressure on lumbar puncture (less than $6 \mathrm{~cm} \mathrm{H}_{2} \mathrm{O}$ ). Thus, each patient showed objective evidence of spontaneous intracranial hypotension, as is required to fulfill ICHD-3 criteria.

Each patient had undergone at least 2 epidural blood or fibrin-glue patch procedures, and 6 patients had undergone surgical treatment of spinal CSF leak or spinal meningeal diverticula.

A CSF-venous fistula was found in $10(19 \%)$ of the 53 patients. The mean age of these 9 women and 1 man was 51.8 years (range 34-64 years). The duration of symptoms ranged from 5 to 121 months (mean 38 months). We were not able to identify any factors associated with an increased likelihood of finding a CSF-venous fistula on DSM (Table 2). CSF-venous fistulas were found in 9 (27\%) of the 33 women and in $1(5 \%)$ of the 20 men, but this result was of only borderline statistical significance $(\mathrm{p}=0.0697)$.

Every CSF-venous fistula was located in the thoracic spine, as shown in Fig. 1. Multiple fistulas were not encountered. The diameters of the venous channel were approximately 1-2 $\mathrm{mm}$. Typical examples of these CSFvenous fistulas demonstrated by DSM are shown in Fig. 2 and Videos 1 and 2.

VIDEO 1. DSM showing a CSF-venous fistula in a 39-year-old man at the T10-11 level on the left (compare with Fig. 2A). Copyright

Wouter I. Schievink. Published with permission. Click here to view.

VIDEO 2. DSM showing a CSF-venous fistula at the right T9-10 level in a 53-year-old woman (compare with Fig. 2C). Copyright

Wouter I. Schievink. Published with permission. Click here to view.

At the time of DSM, opening pressure was unmeasurably low in 1 patient and normal in 9 patients (range 9-13 $\mathrm{cm} \mathrm{H}_{2} \mathrm{O}$ ). Opening pressure at the time of the initial lumbar puncture, however, was below normal in 6 patients (range $0-5.5 \mathrm{~cm} \mathrm{H}_{2} \mathrm{O}$ ).

Before treatment of the spinal CSF-venous fistula, the MiDAS grade was III (moderate disability) in 2 patients and IV (severe disability) in 8 patients.

Four patients were treated initially with percutaneous fibrin sealant injection directed at the site of the CSF-venous fistula. There were no complications from the percutaneous fibrin sealant injection. The injection resulted in complete resolution of symptoms in 1 patient (MiDAS Grade I) (follow-up 6 months), whereas symptoms persisted in the other 3 patients. These 3 patients, as well as the other 6 patients, underwent surgery for their fistula. In 6 patients, the fistula consisted of a network of engorged veins surrounding the proximal spinal nerve root sleeve (with or without cyst development). Treatment consisted of bipolar coagulation of this venous network. In 3 patients, the fistula consisted of a single discrete draining venous channel (Fig. 3) near the origin of, but not involving, the spinal nerve root sleeve. Treatment consisted of clipping and ligation of the venous channel (Video 3 ) in 2 patients and bipolar coagulation of the venous channel in 1 patient.

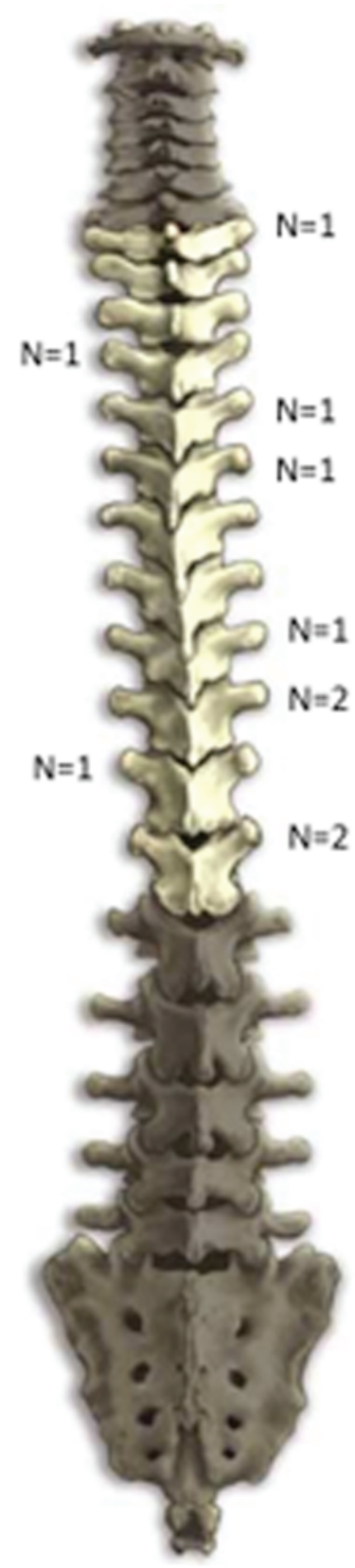

FIG. 1. Frequency of CSF-venous fistulas according to spinal level. The view is from the back as it is on DSM, and the right side is on the right. Figure is available in color online only.

VIDEO 3. Unedited movie clip of surgical treatment of a singlechannel CSF-venous fistula at the right T11-12 level in a 62-yearold woman (compare with Fig. 2B). Copyright Wouter I. Schievink. Published with permission. Click here to view.

There were no complications from the microsurgical treatment. Surgery resulted in complete resolution of symptoms in 8 patients (MiDAS Grade I; follow-up 7-23 months), whereas in 1 patient, symptoms recurred after 4 months. Repeat DSM did not show the CSF-venous fistula, and treatment with multiple epidural blood patches resumed. The stigmata of spontaneous intracranial hypotension on brain MRI resolved in all 6 patients. 


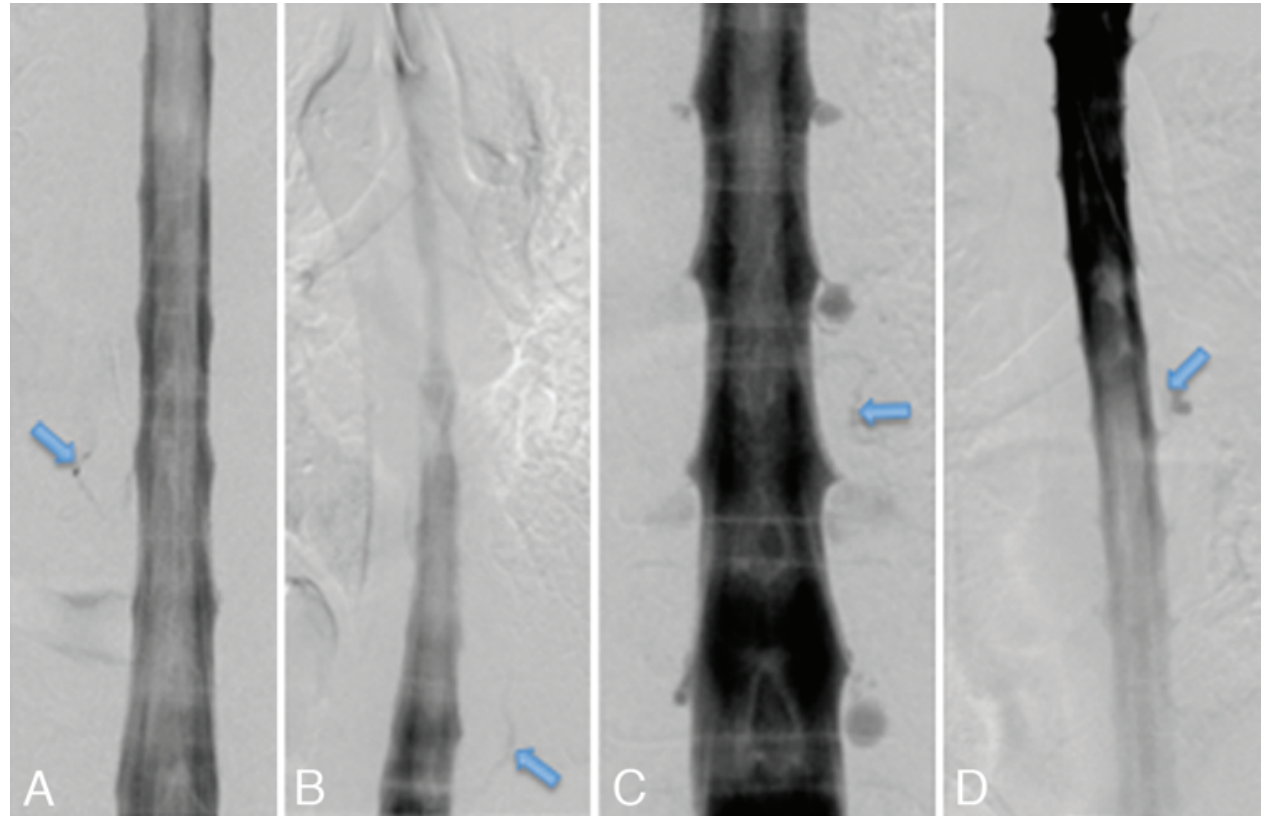

FIG. 2. A-D: CSF-venous fistulas in patients with spontaneous intracranial hypotension: DSM images (frontal projection) showing contrast filling spinal veins (arrows). Figure is available in color online only.

\section{Discussion}

In this study, we found spinal CSF-venous fistulas in approximately one-fifth of the patients with spontaneous intracranial hypotension but no CSF leak identifiable on conventional spinal imaging. Only single CSF-venous fistulas were found, and only in the thoracic spine. Treatment of these fistulas was uncomplicated, usually consisted of surgery, and was successful in $90 \%$ of the patients. Symptom relief was durable, but follow-up has been limited because of the very recent discovery of these fistulas. At surgery, the fistula consisted of either a network of veins surrounding the spinal nerve root sleeve or a single draining venous channel near the origin of the spinal nerve root sleeve. It is not clear if the fistulas represent abnormal anatomical structures or abnormally dilated vascular conduits. Arachnoid granulations along the proximal spinal nerve root sleeves extending into the lumen of a vein have been described, ${ }^{6}$ and intradural and extradural venous engorgement is a common finding in patients with spontaneous intracranial hypotension.?

Spinal CSF-venous fistulas were found in patients with normal brain MRI findings and in those with abnormal brain MRI findings and in patients with previous spinal imaging showing a CSF leak and in those without such a history. These fistulas were found more commonly in women than in men, but this finding did not reach statistical significance.

It is not surprising that these CSF-venous fistulas were not detected by cross-sectional imaging techniques (e.g., MRI or CT myelography, or even conventional myelography). Although not as fast as an arteriovenous fistula, this entity requires rapid imaging with superior spatial and temporal resolution, which is best achieved with DSM.

The inability to find a spinal CSF leak limits treatment options for patients with intractable spontaneous intracra- nial hypotension, and we suggest that DSM be considered for this patient population, although the actual yield of finding a CSF-venous fistula is relatively low.

The underlying cause of spontaneous intracranial hy-
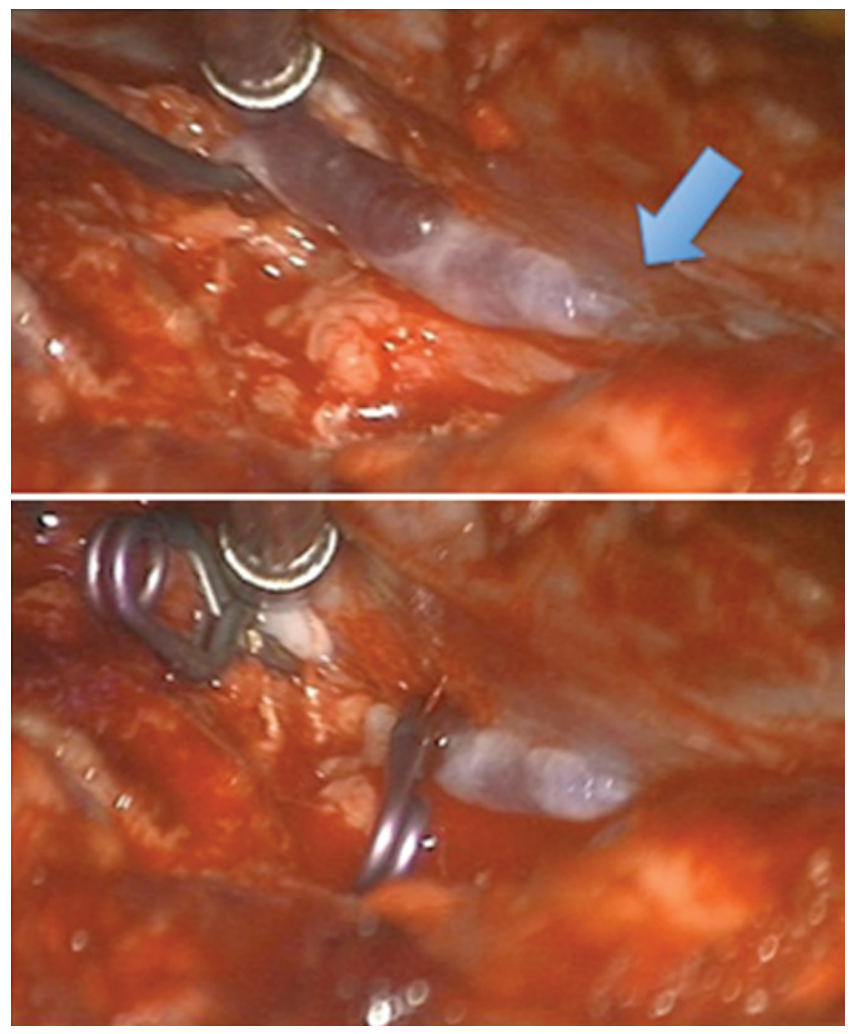

FIG. 3. Intraoperative photographs showing the anatomy of a CSFvenous fistula. Upper: The single venous channel is attached to the lateral common thecal sac (arrow). Lower: The fistula is treated by clip ligation. Figure is available in color online only. 
potension in those with normal results from spinal imaging, including DSM, remains speculative and requires further investigation. A CSF leak below the level of detection of current imaging technology, an intermittent or very slow CSF leak, unusually rapid absorption of spinal CSF, and pooling of CSF are all potential mechanisms underlying spontaneous intracranial hypotension with patients with normal spinal imaging results. However, studies to rule out a CSF leak at the level of the skull base do not need to be performed, because spontaneous intracranial hypotension is not caused by cranial CSF leaks. ${ }^{14}$

\section{Conclusions}

In this study, we found CSF-venous fistulas in approximately one-fifth of the patients with recalcitrant spontaneous intracranial hypotension but no CSF leak identifiable on conventional spinal imaging. We suggest that DSM be considered in this patient population.

\section{References}

1. Akbar JJ, Luetmer PH, Schwartz KM, Hunt CH, Diehn FE, Eckel LJ: The role of MR myelography with intrathecal gadolinium in localization of spinal CSF leaks in patients with spontaneous intracranial hypotension. AJNR Am J Neuroradiol 33:535-540, 2012

2. Bonetto N, Manara R, Citton V, Cagnin A: Spinal subtraction MRI for diagnosis of epidural leakage in SIH. Neurology 77:1873-1876, 2011

3. Chazen JL, Talbott JF, Lantos JE, Dillon WP: MR myelography for identification of spinal CSF leak in spontaneous intracranial hypotension. AJNR Am J Neuroradiol 35:2007-2012, 2014

4. Headache Classification Committee of the International Headache Society: The International Classification of Headache Disorders, 3rd edition (beta version). Cephalalgia 33:629-808, 2013

5. Hoxworth JM, Patel AC, Bosch EP, Nelson KD: Localization of a rapid CSF leak with digital subtraction myelography. AJNR Am J Neuroradiol 30:516-519, 2009

6. Hoxworth JM, Trentman TL, Kotsenas AL, Thielen KR, Nelson KD, Dodick DW: The role of digital subtraction myelography in the diagnosis and localization of spontaneous spinal CSF leaks. AJR Am J Roentgenol 199:649-653, 2012

7. Maillot C: [The space surrounding the spinal cord. Constitution, organization and relationship with the cerebrospinal fluid.] J Radiol 71:539-547, 1990 (Fr)

8. Mokri B: Radioisotope cisternography in spontaneous CSF leaks: interpretations and misinterpretations. Headache 54:1358-1368, 2014

9. Mokri B: Spontaneous CSF leaks: low CSF volume syndromes. Neurol Clin 32:397-422, 2014
10. Schievink WI: Novel neuroimaging modalities in the evaluation of spontaneous cerebrospinal fluid leaks. Curr Neurol Neurosci Rep 13:358, 2013

11. Schievink WI: Spontaneous spinal cerebrospinal fluid leaks and intracranial hypotension. JAMA 295:2286-2296, 2006

12. Schievink WI, Meyer FB, Atkinson JL, Mokri B: Spontaneous spinal cerebrospinal fluid leaks and intracranial hypotension. J Neurosurg 84:598-605, 1996

13. Schievink WI, Moser FG, Maya MM: CSF-venous fistula in spontaneous intracranial hypotension. Neurology 83:472473, 2014

14. Schievink WI, Schwartz MS, Maya MM, Moser FG, Rozen TD: Lack of causal association between spontaneous intracranial hypotension and cranial cerebrospinal fluid leaks. J Neurosurg 116:749-754, 2012

15. Starling A, Hernandez F, Hoxworth JM, Trentman T, Halker $\mathrm{R}$, Vargas BB, et al: Sensitivity of MRI of the spine compared with CT myelography in orthostatic headache with CSF leak. Neurology 81:1789-1792, 2013

16. Stewart WF, Lipton RB, Whyte J, Dowson A, Kolodner K, Liberman JN, et al: An international study to assess reliability of the Migraine Disability Assessment (MIDAS) score. Neurology 53:988-994, 1999

17. Yoo HM, Kim SJ, Choi CG, Lee DH, Lee JH, Suh DC, et al: Detection of CSF leak in spinal CSF leak syndrome using MR myelography: correlation with radioisotope cisternography. AJNR Am J Neuroradiol 29:649-654, 2008

\section{Disclosures}

The authors report no conflict of interest concerning the materials or methods used in this study or the findings specified in this paper.

\section{Author Contributions}

Conception and design: Schievink, Moser, Maya. Acquisition of data: all authors. Analysis and interpretation of data: all authors. Drafting the article: Schievink. Critically revising the article: Schievink. Reviewed submitted version of manuscript: Schievink. Approved the final version of the manuscript on behalf of all authors: Schievink. Statistical analysis: Schievink.

\section{Supplemental Information \\ Videos \\ Video 1. https://vimeo.com/145144062. \\ Video 2. https://vimeo.com/145144061. \\ Video 3. https://vimeo.com/145144060.}

\section{Correspondence}

Wouter I. Schievink, Department of Neurosurgery, Cedars-Sinai Medical Center, 127 S. San Vicente Blvd., Ste. A6600, Los Angeles, CA 90048. email: schievinkw@cshs.org. 